\title{
Carbapenem-Resistant Enterobacteriaceae: A Strategic Roadmap for Infection Control-CORRIGENDUM
}

In the article by Friedman, et al. ${ }^{1}$, the following errors appear in the published version of record:

1) Co-author Mitchell James Schwaber is listed with credentials MD, MPH. The correct credentials are $\mathrm{MD}, \mathrm{MSc}$.

2) Reference 64 contains an error in the author list. Author "Araj F" should be "Araj GF."

3) References 114 and 115 contain errors in the author lists. The phrase "et al." should appear after the $3^{\text {rd }}$ listed author in both reference entries.
4) Reference 124 contains an error in the author list. The author's name is Hayden MK, not Weinstein RA.

The authors apologize for these errors.

REFERENCE

1. Friedman N, Carmeli Y, Walton A, Schwaber M. Carbapenem-Resistant Enterobacteriaceae: A Strategic Roadmap for Infection Control. Infect Control Hosp Epidemiol 2017;38: 580-594. 